\title{
Trends in prevalence of atopic diseases and allergic sensitization in children in Eastern Germany
}

\author{
J. Heinrich*, B. Hoelscher*, C. Frye*, I. Meyer*, M. Wjst*, H-E. Wichmann*,\#
}

Trends in prevalence of atopic diseases and allergic sensitization in children in Eastern Germany. J. Heinrich, B. Hoelscher, C. Frye, I. Meyer, M. Wjst, H-E. Wichmann. (C) ERS Journals Ltd 2002.

ABSTRACT: Trends in prevalence of atopic diseases and allergic sensitization in children from Eastern Germany during the 1990s were analysed.

The study consisted of three regional cross-sectional surveys of a total of 7,632 children (aged 5-14 yrs) in 1992-1993, 1995-1996, and 1998-1999. Information was gathered on atopic diseases and potential predictors by a parental questionnaire. Allergic sensitization for birch, grass, mite, cat, and cladosporium were assessed by radioallergosorbent test (RAST).

After adjustment for age, sex and the study area of the participants, prevalence increased between the first and third survey for hay fever, for asthma and for atopic eczema. The adjusted prevalence of allergic sensitization (RAST $>0.35 \mathrm{kU} \cdot \mathrm{L}^{-1}$ ) showed a decrease, whereas the prevalence of strong sensitization (RAST $\geqslant 17.5 \mathrm{kU} \cdot \mathrm{L}^{-1}$ ) increased significantly, specifically in cohorts born after 1989. Further adjustment for possible determinants of these atopic diseases did not change the trend estimates.

A clear increase in the prevalence of atopic diseases, with the exception of hay fever, was observed as well as a shift towards a stronger allergic sensitization, which might affect the onset of clinical manifestations of atopic diseases.

Differences in the epidemiology of respiratory symptoms, illnesses and allergies between populations living in the former East Germany and those living in the former West Germany have been reported. Among East German children, lower prevalence rates of asthma, and positive skin-prick tests were observed compared to West German children in the early 1990s [1-5]. Similarly, among East German adults, lower specific immunoglobulin (Ig) E levels and lower prevalence rates of asthma, wheezing, positive methacholine-challenge tests, allergic rhinitis, and positive skin-prick tests have been reported compared to those of West German adults [6, 7]. Eur Respir J 2002; 19: 1040-1046.
*GSF-National Research Centre for Environment and Health Institute of Epidemiology and " Ludwig-Maximilians-University of Munich, Chair of Epidemiology, University of Munich, Neuherberg, Germany.

Correspondence: J. Heinrich GSF-Institute of Epidemiology PO Box 1129

D-85758 Oberschleissheim Germany

Fax: 498931873380

E-mail: joachim.heinrich@gsf.de

Keywords: Atopic disease

allergic sensitization

children

East Germany

epidemiology

trend

Received: July 192001

Accepted after revision January 16 2002

This study was supported exclusively by a governmental funding source, the Federal Environmental Agency (Umweltbundesamt) Grants No. $11609 \quad 002$, 116 002/02, 29861724
The prevalence of allergies was similar between East and West Germans born before 1960. Among adults born after 1960, allergies were more prevalent in West compared with East Germany [7, 8]. It has been hypothesized, that since the 1960s, there have been factors present in the West but not in the East which were related to the higher prevalence of allergies among West-German populations [7-9]. After German reunification in 1990, the East-German population rapidly adopted a modern "Western lifestyle" [5,9]. Some of the adopted "Western-lifestyle" factors that may have affected the development of allergies included fewer homes heated with coal or wood [2, 10], better house insulation and tighter windows with a subsequent increase in dampness and moulds [2, 10], more cars (Kraftfahrtbundesamt, Flensburg, Germany, personal communication), "Western" food such as exotic fruits and vegetables [11], and fewer infectious diseases including helminthic infections during early childhood [12].

If these environmental and lifestyle factors contributed to the higher prevalence of allergies among
West Germans, an increase in the prevalence of allergies among East Germans after reunification would be expected. However, it is unknown if this really occurs and whether it is restricted to persons born after the adoption of these Western-like conditions because of the importance of early childhood in the development of allergies.

A possible increase in the prevalence of allergic diseases, symptoms, sensitization, and asthma was analysed using a data set including children who were born after German unification in 1990.

\section{Methods}

\section{Design}

The study consisted of three consecutive regional cross-sectional surveys of children aged 5-14 yrs in 1992-1993, 1995-1996 and 1998-1999. Three study areas differing in air pollution levels were selected. The study included three embedded cohorts, therefore 
children participated in two or three surveys. Data concerning the long-term effects of air pollution on respiratory health in East German children (Bitterfeld Study) [13, 14] was gathered. The data collection and methods have been described in detail in previous studies $[13,14]$.

\section{Study area and sources of air pollution}

The study was conducted in the counties of Bitterfeld, Hettstedt and Zerbst in the State of Sachsen-Anhalt (formerly German Democratic Republic). The three study areas are located in a circle of $100 \mathrm{~km}$ in diameter and share similar meteorological conditions. In the past, the three study areas strongly differed in levels of "classical" air pollutants such as total suspended particulates (TSP) and sulphur dioxide $\left(\mathrm{SO}_{2}\right)$.

After German reunification, the amounts of $\mathrm{SO}_{2}$ and TSP emissions decreased greatly, especially during the years 1990 and 1991. The closure of most industrial plants and the replacement of surface coal by natural gas for domestic heating contributed to the decrease in $\mathrm{SO}_{2}$ and TSP. More detailed descriptions of the study areas have been published previously [13-15].

\section{Subjects}

All first-, third-, and sixth-grade school children who were residents of Zerbst and Hettstedt counties and a subgroup of children from selected schools in Bitterfeld County were invited to participate in this study. All day-care centres and schools in the Zerbst and Hettstedt areas were contacted. Because of the larger area of Bitterfeld county, schools and day-care centres in this county were randomly selected to represent all resident school-aged children. Children were excluded from analysis if they had lived for $<2$ yrs in their current home and their previous home was located $>2 \mathrm{~km}$ away from their current home. The population in all three areas was very homogenous and all participants were White. Mentally- or physically-handicapped children who attended specialized institutions were not included in this study. The University of Rostock Ethics Committee approved the study protocol. Informed consent was obtained from the parents of all participating children.

\section{Respiratory disorders}

As part of the study, teachers distributed questionnaires to the childrens' parents and collected completed questionnaires a week later. The questionnaire contained 78 items that have been described previously [13, 14]. The following health outcomes were analysed in the study: a parental report of a physician's diagnoses (lifetime) of hay fever, asthma, and eczema, as well as parent-reported allergic symptoms such as reddened eyes, sneezing attacks, runny or blocked noses, and itchy rashes.
Assessment of allergic sensitization by immunoglobulin-E measurement

Blood collection, centrifugation and serum storage methods have been described in detail in a previous study [13]. The serum samples of the first and second survey were stored at $-20^{\circ} \mathrm{C}$ until the end of the second survey when they were analysed by the CAPFEIA method using identical batches of reagents for all assay runs for specific IgE to Dermatophagoides pteronyssinus (d1), cladosporium $(\mathrm{m} 2)$, cat $(\mathrm{e} 1)$, mixed grasses (g6), and birch (t3). The serum samples of the third sample were also stored at $-20^{\circ} \mathrm{C}$ until analyses for specific IgE. All measurements were conducted in one laboratory (Pharmacia Diagnostics, Freiburg, Germany). The intra- and inter-assay coefficients of variation were 7\% (Pharmacia, Freiburg, Germany personal communication). The measurement range was $0.35-100 \mathrm{kU} \cdot \mathrm{L}^{-1}$ with a detection limit $>0.35 \mathrm{kU} \cdot \mathrm{L}^{-1}$. Standard curves were set up in duplicate and the samples were assayed in single determinations.

\section{Statistical methods}

Crude prevalence rates for all binary outcome variables were calculated for the participating children in the surveys. Multiple logistic regression analyses were used to adjust the estimates of the temporal changes (second versus first survey and third versus first survey) of the prevalence of physician-diagnosed atopic diseases, allergic symptoms, and sensitization assessed by RAST for covariates or potential confounders. Only children with complete information regarding all covariates were included in the analyses. The results are presented as adjusted odds ratios (OR) with $95 \%$ confidence intervals (CI). Repeated measurements in some of the children were accounted for.

\section{Results}

\section{Participation rates and demography}

In total, parents of 7,632 of 9,630 eligible children aged between 5-14 yrs completed a questionnaire (table 1). The response rates differed slightly between study areas and surveys and ranged between 68.6$92.1 \%$ (table 1). Data for a total of 6,959 questionnaires $(4,949$ children) contributed to the descriptive analyses, where 3,264 children participated in one survey, 1,360 children in two surveys, and 325 children in all three consecutive surveys. Children from the first of the three surveys were quite comparable with regard to sex and parental education to those participating in the other surveys, but children who participated in the first survey were slightly younger (table 1). Changes in the age distribution of the study populations between the first and the other surveys were caused by a general decrease in birth rates after German reunification (which fell by as much as 60\%) in Eastern Germany from 1990-1991 [16]. 
Table 1. - Response, mobility, and characteristics of the study population of surveys 1 (1992-93), 2 (1995-96) and 3 (1998-99)

\begin{tabular}{|c|c|c|c|}
\hline & Survey 1 & Survey 2 & Survey 3 \\
\hline \multicolumn{4}{|l|}{ Responders (questionnaire) } \\
\hline Total & $2470 / 2773(89.1)$ & $2814 / 3765(74.7)$ & $2348 / 3092(75.9)$ \\
\hline Zerbst & $857 / 971(88.3)$ & $748 / 1090$ (68.6) & $695 / 989(70.3)$ \\
\hline Bitterfeld & 799/918 (87.0) & $1255 / 1561(80.4)$ & $961 / 1203(79.9)$ \\
\hline Hettstedt & $814 / 884(92.1)$ & $811 / 1114(72.8)$ & $692 / 900(76.9)$ \\
\hline \multicolumn{4}{|l|}{ Considered in analyses } \\
\hline Total & $2335 / 2773(84.2)$ & $2517 / 3765(66.9)$ & $2107 / 3092(68.1)$ \\
\hline Zerbst & 818/971 (84.2) & $674 / 1090(61.8)$ & $631 / 989(63.8)$ \\
\hline Bitterfeld & $737 / 918(80.3)$ & $1108 / 1561(71.0)$ & $849 / 1203(70.6)$ \\
\hline Hettstedt & $780 / 884(88.2)$ & $735 / 1114(66.0)$ & $627 / 900(69.7)$ \\
\hline \multicolumn{4}{|l|}{ Demographic characteristics } \\
\hline \multicolumn{4}{|l|}{ Age } \\
\hline $5-7$ yrs & $726 / 2335(31.1)$ & $642 / 2517(25.5)$ & $325 / 2107(15.4)$ \\
\hline $8-10$ yrs & $750 / 2335(32.1)$ & $855 / 2517(34.0)$ & $757 / 2107(35.9)$ \\
\hline $11-14 \mathrm{yrs}$ & $859 / 2335(36.8)$ & $1020 / 2517(40.5)$ & $1025 / 2107(48.6)$ \\
\hline Males & $1184 / 2335(50.7)$ & $1354 / 2517(53.8)$ & $1144 / 2107(54.3)$ \\
\hline Higher parental education ${ }^{\#}$ & $958 / 2272(42.2)$ & $1010 / 2398(42.1)$ & $812 / 2023(40.1)$ \\
\hline \multirow{2}{*}{\multicolumn{4}{|c|}{ Other characteristics (predictors }} \\
\hline & & & \\
\hline Low birth weight & $146 / 2240(6.5)$ & $141 / 2373(5.9)$ & $125 / 1881(6.6)$ \\
\hline $\mathrm{No}$ breastfeeding ${ }^{+}$ & $471 / 2321(20.3)$ & $460 / 2498(18.4)$ & $399 / 2004(19.9)$ \\
\hline Parental atopy & $620 / 2335(26.6)$ & $770 / 2517(30.6)$ & $647 / 2031(31.9)$ \\
\hline House made of concrete & $901 / 2245(40.1)$ & $950 / 2447(38.8)$ & $629 / 1929(32.6)$ \\
\hline Child shares bedroom & $1121 / 2297(48.8)$ & $1028 / 2511(40.9)$ & $665 / 2021(32.9)$ \\
\hline Dampness or visible moulds & $438 / 2312$ (18.9) & $568 / 2506(22.7)$ & $466 / 1998(23.3)$ \\
\hline Heating with single oven & $1150 / 2328(49.4)$ & $931 / 2421(38.5)$ & $751 / 1994(37.7)$ \\
\hline Carpet in child's room & $2173 / 2329(93.3)$ & $2026 / 2479(81.7)$ & $1845 / 2008(91.9)$ \\
\hline ETS exposure & $1076 / 2305(46.7)$ & $1074 / 2489(43.1)$ & $915 / 2084(43.9)$ \\
\hline Contact to cats & $750 / 2300(32.6)$ & $815 / 2510(32.5)$ & $722 / 2000(36.1)$ \\
\hline Child attended day-care centre ${ }^{f}$ & $2062 / 2314(89.1)$ & $2218 / 2499(88.8)$ & $1764 / 2061(85.6)$ \\
\hline
\end{tabular}

Data are presented as respondents/total with \% in parentheses. ETS: environmental tobacco smoke. ${ }^{\#}$ : education of father or mother $\geqslant 12 \mathrm{yr} ;{ }^{\uparrow}: \leqslant 2700 \mathrm{~g} ;{ }^{+}:<4$ weeks; ${ }^{\S}$ : current or prior; ${ }^{f}$ : before $1 \mathrm{yr}$ of age.

Temporal changes of respiratory disorders, demographic characteristics and potential predictors

Temporal changes of characteristics used for adjustment of atopic outcomes are shown in table 1. Crude prevalence of atopic diseases, allergic symptoms and RAST sensitization in the three surveys are shown in table 2. For nearly all atopic diagnoses, a continuous increase of prevalence was found between the three surveys. Regarding allergic symptoms for itchy rash only, an increasing trend of crude prevalence was found. A similar trend was seen for strong allergic sensitization (RAST $\geqslant 17.5 \mathrm{kU} \cdot \mathrm{L}^{-1}$ ), while no clear tendencies were shown for the prevalence of detectable specific IgE antibodies (RAST $>0.35 \mathrm{kU} \cdot \mathrm{L}^{-1}$ ). However, the age distributions shifted towards higher ages (table 1) and affected the crude prevalence estimates.

After adjustment for age, sex and study area, increases in prevalence were found for hay fever, asthma and atopic eczema comparing the third and the second survey with the first survey (fig. 1). The prevalence of allergic sensitization (any specific $\operatorname{IgE}$ $>0.35 \mathrm{kU} \cdot \mathrm{L}^{-1}$ ) adjusted for area, sex, and age showed statistically significant decreases for the comparison for the third and the second with the first survey. Prevalence of strong sensitization to any allergens (RAST $\geqslant 17.5 \mathrm{kU} \cdot \mathrm{L}^{-1}$ ) showed statistically significant increases ( $\mathrm{p}$-trend 0.021 , OR third versus first survey
1.33 (1.05-1.67)), OR second versus first survey 1.28 (1.05-1.56)) (fig. 1).

Further adjustment for parental education, parental atopy, housing conditions such as dampness, exposure to emissions from gas cooking and environmental tobacco smoke, crowding, carpeting, day-care attendance, contact with cats, breast feeding, low birth weight, and season of examination (only for RAST) did not change the OR (data not shown). Obviously, all these potential influencing factors which are known to have partly changed over time (table 1) contribute slightly to the increase of prevalence of atopic diseases and strong allergic sensitization (RAST $\geqslant 17.5 \mathrm{kU} \cdot \mathrm{L}^{-1}$ ).

A higher prevalence of allergic sensitization, with increasing cut-off points for any specific antibodies during 1992-1999, was found (fig. 1). This pattern was mainly caused by the statistically significant increasing prevalence of specific sensitization to birch pollen and mites (fig. 2)

Age-related effects on the prevalence of atopic outcomes were distinguished from birth-cohort related effects (table 3). The adjusted prevalence of asthma increased continuously in all age groups and even within the three birth cohort subgroups that were born before 1990, the year of German reunification. The adjusted prevalence of hay fever was only marginally increased. A remarkable increase in the 
Table 2. - Crude prevalence of atopic diagnoses and symptoms and radioallergosorbent test (RAST)-sensitization in Eastern German children aged 5-14 yrs in Surveys 1 (1992-93), 2 (1995-96) and 3 (1998-99)

\begin{tabular}{|c|c|c|c|}
\hline & Survey 1 & Survey 2 & Survey 3 \\
\hline \multicolumn{4}{|l|}{ Physician's diagnoses $\#$} \\
\hline Hay fever & $102 / 2327(4.4)$ & $129 / 2517(5.1)$ & $129 / 2103(6.1)$ \\
\hline Asthma & $61 / 2319(2.6)$ & $88 / 2517(3.5)$ & $98 / 2062(4.8)$ \\
\hline Eczema & $239 / 2327(10.3)$ & $259 / 2517(10.3)$ & $241 / 2103(11.5)$ \\
\hline Any allergy against: & $316 / 2312(13.7)$ & 490/2502 (19.6) & $505 / 2076(24.3)$ \\
\hline Food & $39 / 2305(1.7)$ & $60 / 2498(2.4)$ & $72 / 2062(3.5)$ \\
\hline Drug & $53 / 2305(2.3)$ & $39 / 2498(1.6)$ & $47 / 2062(2.3)$ \\
\hline Pollen & $106 / 2305(4.6)$ & $242 / 2498(9.7)$ & $230 / 2062(11.2)$ \\
\hline Animal dander & $48 / 2305(2.1)$ & $152 / 2498(6.1)$ & $152 / 2062(7.4)$ \\
\hline Fungi & $10 / 2305(0.4)$ & $66 / 2498(2.6)$ & $68 / 2062(3.3)$ \\
\hline \multicolumn{4}{|l|}{ Allergy symptoms } \\
\hline Conjunctivitis $^{\#}$ & $153 / 2302(6.7)$ & $189 / 2513(7.5)$ & $125 / 2076(6.0)$ \\
\hline Sneezing ${ }^{\#}$ & $193 / 2302(8.4)$ & $251 / 2513(10.0)$ & $176 / 2076(8.5)$ \\
\hline Runny nose ${ }^{\#}$ & $201 / 2302(8.7)$ & $234 / 2513(9.3)$ & $165 / 2076(8.0)$ \\
\hline Itchy $\mathrm{rash}^{+}$ & $342 / 2312(14.8)$ & $449 / 2509$ (17.9) & $395 / 2055(19.2)$ \\
\hline \multicolumn{4}{|c|}{ RAST class $>0\left(0.35 \mathrm{kU} \cdot \mathrm{L}^{-1}\right)$} \\
\hline Dust mite & $303 / 2016(15.0)$ & $327 / 2106(15.5)$ & $320 / 1730(18.5)$ \\
\hline Cat & $141 / 1977(7.1)$ & $152 / 2106(7.2)$ & $149 / 1729(8.6)$ \\
\hline Cladosporium & $82 / 1721(4.8)$ & $87 / 2104(4.1)$ & $71 / 1728(4.1)$ \\
\hline Birch pollen & $186 / 1702(10.9)$ & 244/2098 (11.6) & $204 / 1728(11.8)$ \\
\hline Grass pollen & 470/1979 (23.7) & $393 / 2104(18.7)$ & $341 / 1729(19.7)$ \\
\hline \multicolumn{4}{|c|}{ RAST class $>3\left(17.5 \mathrm{kU} \cdot \mathrm{L}^{-1}\right)$} \\
\hline Dust mite & $44 / 2016(2.2)$ & $75 / 2106(3.6)$ & $86 / 1730(5.0)$ \\
\hline Cat & $17 / 1977(0.9)$ & $23 / 2106(1.1)$ & $16 / 1729(0.9)$ \\
\hline Cladosporium & $12 / 1721(0.7)$ & 14/2104 (0.7) & $4 / 1728(0.2)$ \\
\hline Birch pollen & $21 / 1702(1.2)$ & $50 / 2098(2.4)$ & $48 / 1728(2.8)$ \\
\hline Grass pollen & $116 / 1979(5.9)$ & $110 / 2104(5.2)$ & $95 / 1729(5.5)$ \\
\hline
\end{tabular}

Data are presented as respondents/total with \% in parentheses. ${ }^{\#}$ : last year; ${ }^{\top}$ : as reported by parents; ${ }^{+}$: lifetime.

adjusted prevalence of atopic eczema was found for children born after German reunification. The latter finding correlates well with the increased prevalence of strong allergic sensitization in these specific birth cohorts (table 3). The increase of prevalence of strong allergic sensitization was found in the two cohorts born in 1990 and 1993, whereas only a marginal increase was found in the cohorts born before 1990 . The strongest increase of prevalence of allergic sensitization was seen in children aged 6 yrs who were born in the years 1990 and 1995 (table 3). However, the prevalence of detectable specific IgE did not increase with increasing year of birth (data not shown).

\section{Discussion}

\section{Summary}

In summary, an increase in the adjusted prevalence of asthma and atopic eczema and a marginally significant increase in hay fever was found. A shift towards higher prevalence of a stronger sensitization was observed, however, the prevalence of allergic sensitization to any of the most common aeroallergens showed a marginally decreasing trend. The adjusted prevalence of any strong allergic sensitization (RAST $\geqslant 17.5 \mathrm{kU} \cdot \mathrm{L}^{-1}$ ) increased statistically significantly in parallel with strong allergic sensitization to mite and birch pollen. Children who were born after German reunification showed an increased prevalence for strong allergic sensitization and atopic eczema, whereas the prevalence for asthma was found to be increased over all birth cohorts.

\section{Comparison with other studies}

Three large studies have been specifically designed to study temporal changes of allergic respiratory health in East German children (table 4). The results of these three studies consistently showed increasing prevalence for hay fever, atopic eczema and asthma, although not for asthma in the Leipzig study [19-21]. The increasing prevalence of asthma was supported by findings of the Bitterfeld Study [22], which found an increasing prevalence of bronchial hyperresponsiveness (BHR). Despite a certain heterogeneity of the results on temporal changes of allergic sensitization (table 4), the two studies showed consistently an increase in prevalence of allergic sensitization to birch pollen and house dust mites, whereas no [17, 18] or even decreasing [22] tendencies were reported for grass pollen. Furthermore, both studies found a consistent increase of prevalence of strong allergic sensitization. One might speculate that the shift to strong allergic sensitization might cause a decreased prevalence of mild sensitization if the population at risk is more or less stable.

There are a number of speculations for the apparent discrepancy in findings between the three studies. Firstly, the studies differed in the degree of urbanization as a result of a more rapid westernization in the 

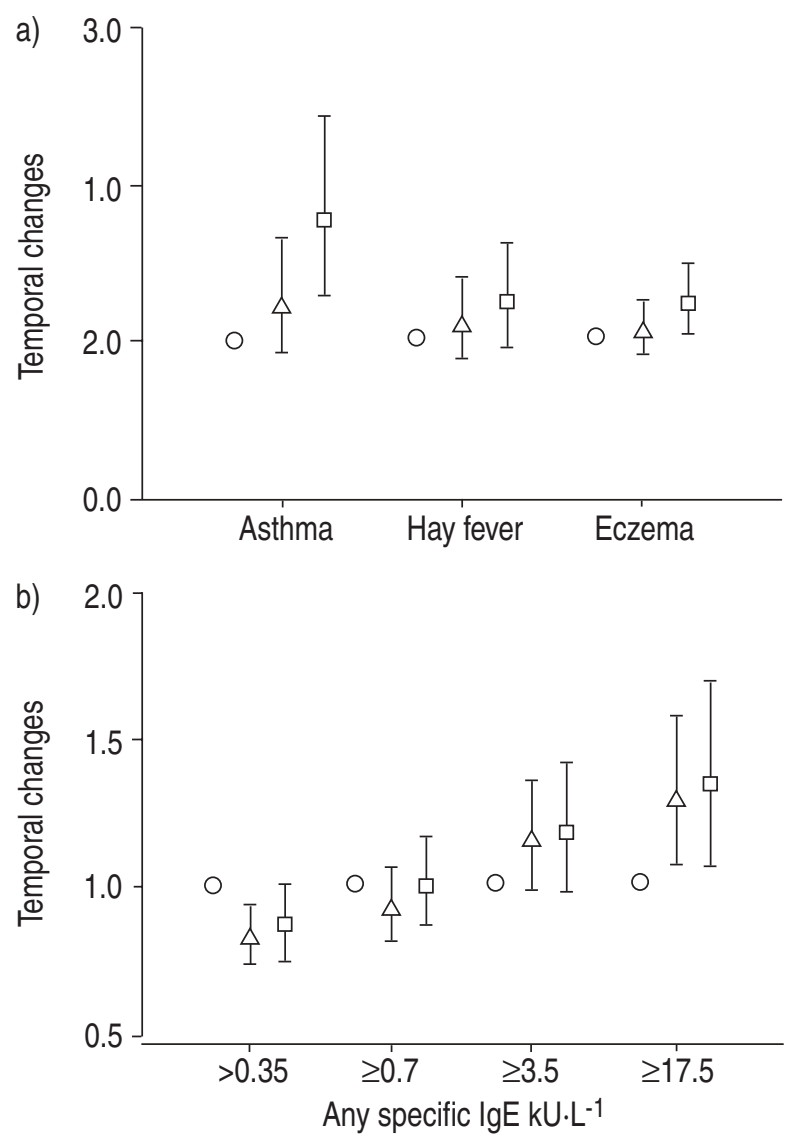

Fig. 1.-Temporal changes of prevalence of atopic diseases and allergic sensitization in children aged 5-14 yrs from three crosssectional surveys in 1992-1993 ( $\bigcirc$, reference), 1995-1996 $\triangle \triangle$ ) and 1998-1999 ( $\square$ ) adjusted for area, age and sex. Data are presented as odds ratio and $95 \%$ confidence intervals. Ig: immunoglobulin.

urban areas. The degree of urbanization is known to be associated with prevalence of atopic diseases [23]. Secondly, the children of the three studies have different age ranges indicating different cohorts of children prior to and after German reunification and therefore with specific conditions during early life. Thirdly, methodological problems, in particular with standardization of the multitest Stallergenes devices used in the Leipzig study, could not be excluded [24]. Finally, the time frames of exposure during early childhood were different.

\section{Possible reasons for the increased prevalence of atopic diseases}

Besides these speculations, the discrepant study results should be interpreted with caution. Assuming a "sensitization window" during the first few months of life [25], one would expect that children who were born after German reunification, when tremendous changes in living and social conditions began would be more affected than children born before. In accordance with this assumption, studies did not find any increase of prevalence of allergic sensitization in children born prior to the reunification [2, 21]. Only the recently published expanded studies in Sachsen-Anhalt,

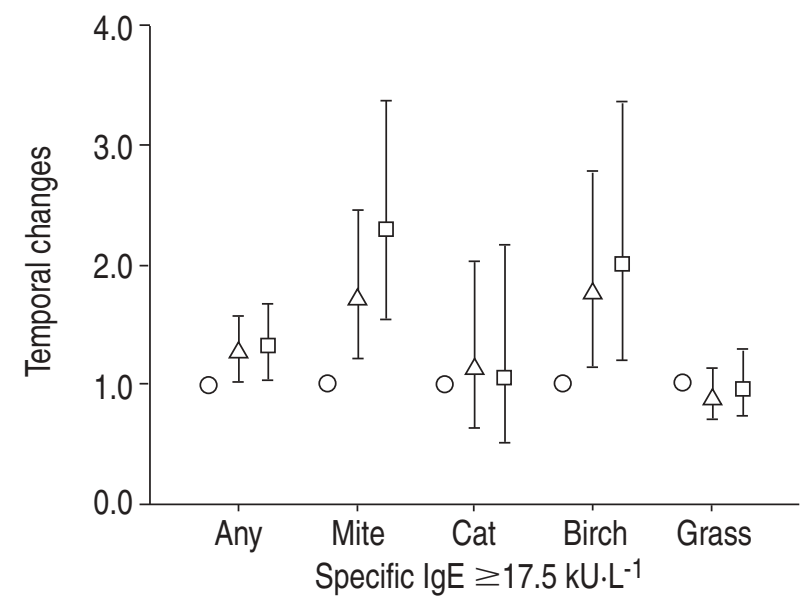

Fig. 2.- Temporal changes of strong allergic sensitization to mite, cat, birch and grass pollen in children aged 5-14 yrs from three crosssectional surveys in 1992-1993 ( $\bigcirc$, reference), 1995-1996 $\triangle \triangle$ ) and 1998-1999 ( $\square$ ) adjusted for area, age and sex. Data are presented as odds ratio and $95 \%$ confidence intervals. Ig: immunoglobulin.

which included children born after German reunification for the first time, showed an increasing trend of prevalence of allergic sensitization [17].

The potential predictors of trends of allergic diseases did not affect the trend estimates for the Sachsen-Anhalt study [17], the Leipzig study [19] nor this study. Although remarkable, changes were found regarding several indoor factors, which may influence the development of allergic diseases in the three studies, inclusion of these factors in a multivariate

Table 3.-Adjusted prevalence of asthma, hay fever, atopic eczema and allergic sensitization by birth cohort and survey

\begin{tabular}{|c|c|c|c|c|c|}
\hline & \multicolumn{5}{|c|}{ Year } \\
\hline & 1981 & 1984 & 1987 & 1990 & 1993 \\
\hline \multicolumn{6}{|l|}{ Hay fever } \\
\hline \multicolumn{6}{|l|}{ Age } \\
\hline $6 \mathrm{yrs}$ & & & $2.1^{\#}$ & $2.3^{\pi}$ & $2.3^{+}$ \\
\hline 9 yrs & & $4.1^{\#}$ & $4.0^{\circ}$ & $5.0^{+}$ & \\
\hline $12 \mathrm{yrs}$ & $5.4^{\#}$ & $5.9^{\natural}$ & $6.1^{+}$ & & \\
\hline \multicolumn{6}{|l|}{ Asthma } \\
\hline \multicolumn{6}{|l|}{ Age } \\
\hline 6 yrs & & & $2.1^{\#}$ & $2.7^{\bullet}$ & $3.9^{+}$ \\
\hline 9 yrs & & $2.1^{\#}$ & $2.2^{\bullet}$ & $4.6^{+}$ & \\
\hline $12 \mathrm{yrs}$ & $2.2^{\#}$ & $3.0^{\circ}$ & $3.6^{+}$ & & \\
\hline \multicolumn{6}{|l|}{ Eczema } \\
\hline \multicolumn{6}{|l|}{ Age } \\
\hline $6 \mathrm{yrs}$ & & & $8.6^{\#}$ & $11.0^{\bullet}$ & $13.0^{+}$ \\
\hline 9 yrs & & $8.6^{\#}$ & $9.9^{\circ}$ & $11.8^{+}$ & \\
\hline $12 \mathrm{yrs}$ & $9.6^{\#}$ & $9.1^{\oplus}$ & $10.2^{+}$ & & \\
\hline \multirow{3}{*}{\multicolumn{6}{|c|}{$\begin{array}{l}\text { Strong allergic } \\
\text { sensitization any } \\
\operatorname{IgE} \geqslant 17.5 \mathrm{kU} \cdot \mathrm{L}^{-1}\end{array}$}} \\
\hline & & & & & \\
\hline & & & & & \\
\hline \multicolumn{6}{|l|}{ Age } \\
\hline $6 \mathrm{yrs}$ & & & $3.9^{\#}$ & $7.4^{\pi}$ & $7.1^{+}$ \\
\hline 9 yrs & & $8.1^{\#}$ & $8.7^{{ }^{\circ}}$ & $11.9^{+}$ & \\
\hline $12 \mathrm{yrs}$ & $10.2^{\#}$ & $11.6^{\circ}$ & $10.3^{+}$ & & \\
\hline
\end{tabular}

Data are presented as \%. ${ }^{*}$ : first survey in 1992-1993; ๆ: second survey in 1995-1996; ${ }^{+}$: third survey in 1998-1999. 
Table 4.-Comparison of trends of prevalence of allergic diseases in Eastern German children during the 1990s

\begin{tabular}{|c|c|c|c|}
\hline & $\begin{array}{l}\text { Bitterfeld Study } \\
\text { (the current study) } \\
1992,1995,1998\end{array}$ & $\begin{array}{c}\text { Sachsen-Anhalt } \\
\text { Sachsen-Study } \\
\text { 1991-2000 }\end{array}$ & $\begin{array}{c}\text { Leipzig } \\
1992,1995\end{array}$ \\
\hline Age yrs & $5-14$ & $5-7$ & $9-11$ \\
\hline Subject $n$ & 7632 & $\sim 22000$ & 4520 \\
\hline Hayfever $^{+}$ & $(\uparrow)$ & $\uparrow$ & $\uparrow$ \\
\hline Asthma $^{+}$ & & $\uparrow$ & $=$ \\
\hline Eczema $^{+}$ & $\uparrow$ & $\uparrow$ & $(\uparrow)$ \\
\hline \multicolumn{4}{|l|}{ Sensitization } \\
\hline SPT & $\mathrm{NE}$ & $\uparrow(\mathrm{HDM})$ & $\uparrow($ any SPT) \\
\hline RAST & $\begin{array}{c}\downarrow\left(\text { any RAST >0.35 kU· } \mathrm{L}^{-1}\right) \\
\uparrow\left(\text { RAST } \geqslant 17.5 \mathrm{kU} \cdot \mathrm{L}^{-1}\right)\end{array}$ & $\uparrow\left(\right.$ birch) $\left(\mathrm{RAST} \geqslant 0.7 \mathrm{kU} \cdot \mathrm{L}^{-1}\right)$ & NE \\
\hline $\mathrm{BHR}^{\S}$ & $\uparrow(\mathrm{HDM}$, birch $\left.) \underset{\uparrow}{(\mathrm{RAST}} \geqslant 17.5 \mathrm{kU} \cdot \mathrm{L}^{-1}\right)$ & $\uparrow(\mathrm{HDM})\left(\mathrm{RAST} \geqslant 0.7 \mathrm{kU} \cdot \mathrm{L}^{-1}\right)$ & $=$ \\
\hline
\end{tabular}

SPT: skin-prick test; RAST: radioallergosorbent test; BHR: bronchial hyperresponsiveness; HDM: house dust mite; NE: not examined; $\uparrow$ : significant increase of prevalence; $=:$ no significant change in prevalence; $(\uparrow)$ : marginally significant increase in prevalence; $\downarrow$ : significant decrease of prevalence. ${ }^{\#}:[17,18] ;{ }^{\uparrow}:[19] ;{ }^{+}:$lifetime prevalence of doctors diagnoses; ${ }^{\S}$ : decrease of forced expiratory volume in one second $\geqslant 9 \%$ from baseline after cold air challenge.

regression model only marginally changed the crude estimates for temporal changes.

The prevalence of the three oldest birth cohorts did not show any remarkable differences in prevalence of strong allergic sensitization and atopic eczema (table 3). In particular, 6-yr-old children born after the German reunification showed a higher prevalence of strong allergic sensitization and atopic eczema than children of the same age born before 1990. A similar, although attenuated association was found for the 9-yr-old children (table 3). These results support the hypothesis that early life is an important factor in the development of atopic diseases. Furthermore, it argues stongly against the assumption that the trend is exclusively driven by an increased awareness.

The increased prevalence of atopic diseases in Eastern German children is at least partly due to the change in the Eastern German housing and living conditions, and could be assessed by parallel examinations of children in Eastern and Western Germany. Preliminary results of the only study of this type showed a steeper increase in prevalence of asthma, hay fever, and allergic sensitization to birch pollen, house dust mites, and milk in Eastern German children [17].

The levels of TSP and $\mathrm{SO}_{2}$ decreased tremendously during the 1990s in Eastern Germany [14, 15]. Nevertheless, this ecological association between the decreasing levels of air pollutants and the prevalence of atopic diseases should be interpreted with caution. No valid conclusion on the effect of air pollution on the development of atopic disease could be drawn from this association. It was argued that the lower prevalence of asthma and hay fever in Eastern European countries indicated that air pollution does not play a major role in the onset of these diseases. This might be relevant for TSP and $\mathrm{SO}_{2}$, but may be irrelevant for specific chemical or physical properties of particulate matter and gaseous pollutants such as nitrogen dioxide. Whether the increase of nucleation mode particles concentration (particles $<30 \mathrm{~nm}$ in geometric diameter) in the study areas between 1993 and 1999 [15] had any effect on the onset of atopic diseases requires further investigation.

Furthermore, it could be argued that the increasing prevalence of atopic diseases is indirectly caused by the decreased exposure to "classical" pollutants such as TSP and $\mathrm{SO}_{2}$. The decline of these pollutants goes along with major improvements of nonallergic respiratory health in Eastern German children [14, 20]. If these pollutants affect the onset of nonspecific respiratory infections, particularly during early life, one may speculate that the decrease of prevalence of these (ambient) pollution-related infections might enhance the development of atopic diseases.

\section{Strengths and limitations of this study}

A major strength in this study is that identical methods including an identical questionnaire were used in the three surveys. Specific IgE levels were analysed by the CAP-FEIA system (Pharmacia, Freiburg, Germany) using the same laboratory. Since temporal changes of prevalence of strong allergic sensitization differed between the three age groups (table 3), differences in analytical issues are unlikely. One potential strength of the analysis is that the results of the three study areas were pooled. There were differences in several health indicators, e.g. allergic status between children of the three study areas. These differences are described in detail elsewhere [22]. However, the direction and magnitude of the changes in each area were similar (data not shown), and when interaction term with study area was included in the multiple logistic regression model, comparable trends were found for each study location. A further potential limitation is the lower participation rate in the second and third survey. The lower participation rates did not lead to a selection bias regarding education, which is a marker for socioeconomic status. Because there was no difference in the distribution of educational levels of parents participating in the three surveys, this selection bias as regarded as negligible. 
To conclude, the prevalence of asthma, hay fever, and atopic eczema increased in Eastern German children. Although the overall prevalence of allergic sensitization to common aeroallergens did not increase, the prevalence of strong allergic sensitization (RAST $\geqslant 17.5 \mathrm{kU} \cdot \mathrm{L}^{-1}$ ) increased, which might affect the onset of clinical manifestations of atopic disease. The increased prevalence in children born after 1989 indicated that a "Western lifestyle" in very early childhood might drive the temporal changes of prevalence of atopic diseases and strong allergic sensitization.

\begin{abstract}
Acknowledgements. The authors would like to thank H. Bach, H. Adam, B. Wilde, H. Wolff, D. Bodesheim, I. Hörhold, I. Keller, G. Burmester, J. Rudzinski, B. Hollstein, H. Machander, R. Müller, D. Albrecht, and C. Boettcher for drawing the blood samples, gathering regional data and local assistance; H. Schneller for data handling; T. Tuch and M. Pitz for air pollution measurements in 1993 and 1999; all teachers in Hettstedt, Zerbst, and Bitterfeld, and the local school authorities and healthcare centres for their support; and all parents and children for their participation.
\end{abstract}

\section{References}

1. Klein K, Dathe R, Göllwitz S, Jäger L. Allergies - a comparison between two vocational schools in East and West Germany. Allergy 1992; 47: 259.

2. Krämer U, Behrendt $\mathrm{H}$, Dolgner R, et al. Prevalence of respiratory disease, allergies and allergic sensitization. Allergologie 1999; 22: 27-37.

3. von Mutius E, Fritzsch C, Weiland SK, Röll G, Magnusson H. Prevalence of asthma and allergic disorders among children in united Germany; a descriptive comparison. BMJ 1992; 305: 1395-1399.

4. von Mutius E, Martinez FD, Fritzsch C, Nicolai T, Roell G, Thiemann H-H. Prevalence of asthma and atopy in two areas of West and East Germany. Am J Respir Crit Care Med 1994; 149: 358-364.

5. Trepka MJ, Heinrich J, Wichmann HE. The epidemiology of atopic diseases in Germany: An East-West Comparison. Rev Environm Health 1996; 11: 119-131.

6. Nicolai T, Bellach B, Mutius EV, Thefeld W, Hoffmeister $H$. Increased prevalence of sensitization against aeroallergens in adults in West compared with East Germany. Clin Exp Allergy 1997; 27: 886-892.

7. Nowak D, Heinrich J, Jorres R, et al. Prevalence of respiratory symptoms, bronchial hyperresponsiveness and atopy among adults: west and east Germany. Eur Respir J 1996; 9: 2541-2552.

8. Heinrich J, Nowak D, Wassmer $\mathrm{G}$, et al. Agedependent differences in the prevalence of allergic rhinitis and atopic sensitization between an eastern and a western German city. Allergy 1998; 53: 89-93.

9. Wichmann HE. Possible explanation for the different trends of asthma and allergy in east and west Germany. Clin Exp Allergy 1996; 26: 621-623.
10. von Mutius E, Illi $\mathrm{S}$, Nicolai $\mathrm{T}$, Martinez FD. Relation of indoor heating with asthma, allergic sensitisation, and bronchial responsiveness: survey of children in south Bavaria. BMJ 1996; 312: 1448-1450.

11. Winkler $\mathrm{G}$, Brasche S, Heinrich J. Trends in food intake in adults from the city of Erfurt before and after the German reunification. Ann Nutr Metab 1997; 41: 283-290.

12. Dold S, Heinrich J, Wichmann HE, Wjst M. Ascarisspecific $\operatorname{IgE}$ and allergic sensitization in a cohort of school children in the former East Germany. J Allergy Clin Immunol 1998; 102: 414-420.

13. Heinrich J, Hoelscher B, Wjst M, Ritz B, Cyrys J, Wichmann HE. Respiratory diseases and allergies in two polluted areas in east germany. Environ Health Perspect 1999; 107: 53-62.

14. Heinrich J, Hoelscher B, Wichmann HE. Decline of ambient air pollution and respiratory symptoms in children. Am J Respir Crit Care Med 2000; 161: 19301936.

15. Pitz M, Kreyling WG, Hölscher B, Cyrys J, Wichmann HE, Heinrich J. Change of the ambient particle size distribution in East Germany between 1993 and 1999. Atmos Environ 2001; 35: 4357-4366.

16. Report. Wiesbaden, Statistisches Bundesamt, 1994.

17. Krämer U, Behrendt $H$, Oppermann $H$, Schäfer $T$, Ranft U, Ring J. Differences in trends of allergies and allergic sensitization in six year old children from East and West Germany between 1991 and 2000. Epidemiol 2001; 12: S86.

18. Schafer T, Kramer U, Behrendt H, Ring J. Prevalence and trend of atopic eczema in East and West Germany: Results from repeated cross-sectional studies between 1991 and 2000. Epidemiol 2001; 12: S73.

19. von Mutius E, Weiland SK, Fritzsch C, Duhme H, Keil U. Increasing prevalence of hay fever and atopy among children in Leipzig, East Germany. Lancet 1998; 351: 862-866.

20. Kramer U, Behrendt H, Dolgner R, et al. Airway diseases and allergies in East and West German children during the first 5 years after reunification: time trends and the impact of sulphur dioxide and total suspended particles. Int J Epidemiol 1999; 28 : 865-873.

21. Heinrich J, Hoelscher B, Jacob B, Wjst M, Wichmann HE. Trends in allergies among children in a region of former East Germany between 1992-1993 and 1995-1996. Eur J Med Res 1999; 4: 107-113.

22. Frye C, Heinrich J, Wjst M, Wichmann HE. Increasing prevalence of bronchial hyperresponsiveness in three selected areas in East Germany. Eur Respir $J$ 2001; 18: 451-458.

23. Heinrich J, Frye C, Hölscher B, Meyer I, Wjst M, Wichmann HE. Heuschnupfen- und Asthmaprävelenz bei Kindern sind abhängig von der Gemeindegröße. Allergo J 2001; 10: 89-94.

24. Heinrich J, Wjst M. Increase of allergy in East Germany. Lancet 1998; 351: 1813.

25. Holt P. Programming for responsiveness to environmental antigens that trigger allergic respiratory disease in adulthood is initiated during the perinatal period. Environ Health Perspect 1998; 106: Suppl. 3, 795-800. 